\title{
Influences of CAI Teaching Pattern on English Writing
}

\author{
Zhang Dandan \\ Wuchang University of Technology, No. 16 Jiaxia Road, Wuhan, Hubei 430223, China
}

\begin{abstract}
With its rich resources, computers play a more and more important role in foreign language teaching. It quickly became one of the most effective teaching tools in English teaching reform in Colleges and universities. As it is very convenient, CAI teaching emphasizes the sharing of resources in English writing courses and it encourages learners to actively participate in the class. This paper analyzes the effect of network teaching environment for College English majors in writing course. The paper also aims to prove that CAI Teaching pattern can not only greatly arouse the interest and motivation of students, but also can inspire English majors to improve their writing ability and communication ability.
\end{abstract}

KEYWORD: CAI teaching; TRP; English writing; Effects

\section{THE THEORETICAL BASIS OF CAI TEACHING OF ENGLISH WRITING}

\subsection{Constructivism}

Constructivist learning theory (Constructivism) holds the idea that knowledge is not taught by teachers. Instead, it is acquired by the learner in a certain social and cultural background with the help of outside media and necessary learning materials. It is an active construction process. In this theory, "Situation", "cooperation", "conversation" and "meaning construction" are the basic four elements of constructivism. Language learners gradually construct new knowledge about the external world in the interaction process with the external environment so that they can develop their own cognitive structure.

For example, CAI teaching can quickly help the language learners to cultivate their ability of selfstudy, solve problems independently, expand their thinking and stimulate their inspiration. In the network and CAI teaching environment, teachers will give full play to students' autonomous learning in the writing course. Besides, through establishing appropriate situation relevant to the writing theory, teachers can help the students to construct the knowledge structure. In order to finish the writing task, the teacher will encourage students to find a lot of vivid examples, quotes, cases closely related to the topic from internet. In this process, students could fully understand the writing task, discuss the topic with their partners or group members and single out the best supporting details from the internet.

To be specific, when I explain the methods to develop a paragraph by comparison and contrast, I first divide the students into several groups. And then each group is required to watch a video clip from their computers about the difference and similarities between men and women, including their attitudes toward TV series, traveling, communication, shopping habits, housework, diet, handbags and ideal spouse, etc. After that, each student will write down those differences and similarities with some useful expressions. Before the teacher's comments, each group will make a summary of their members' opinions and share with each other. Finally, the speakers from each group will exchange their ideas and evaluate each other's work. In this process, students will get a profound understanding about "comparison" and "contrast". Besides, they will issue their opinions bravely and confidently. Team spirit can also be practiced in this way.

\subsection{Humanism}

Humanism advocates affective teaching--- "teaching process is mainly non personal communication, emotional exchange, instant creation and socialization". The teaching theory emphasizes interpersonal relationship, emotion effect and the subconscious activities. Therefore, the teacher should treat students with a sincere attitude and 
teachers and students should be honest with each other in the exchanges. In addition, teachers should encourage students to express their feelings, thoughts, ideas instead of putting their own ideas, thoughts and feelings to students.

Most importantly, teachers should respect students' individual experience and pay attention to their feelings and opinions, and each student is recognized as its own value of an individual. Moreover, the teacher should not only appreciate and praise the advantages of students but also the tolerate their disadvantage.

\subsection{Interaction Approach}

An interactive approach was put forward by H. D. Brown. He divided the writing tasks into ten steps--"Games, Role-Play and Simulation, Drama, Projects, Interview, Brainstorming, Information gap, Jigsaw, Problem solving and Decision-making, Opinion Exchange." [1]. Besides, interaction approach. For a writing team, the emotional support and questioning with each other are the most efficient way to help students to deepen their thoughts and understanding.

Let's take the writing topic of "left-behind children" for example, with the help of computers, teachers could encourage students to search some target words phrases and some sentence patterns related to the theme and common sentence patterns before writing. Each writing member is also encouraged to surf those typical examples and reviews about the topic within the specified time.

Then each writing team will discuss the topic with those vivid phrases and idiomatic expressions for fifteen minutes. After that, the teacher can invite those speakers recommended by team members to exchange their opinions with each other. Finally, they will summarize their opinions and evaluate each others comments before they finish they write their first draft. Overall, in the interaction process, we can activate the learning through the reflection on their familiar problems, situation and countermeasures.

\section{ENGLISH WRITING TEACHING PRACTICE UNDER CAI ENVIRONMENT}

\subsection{Teaching resource platform}

Teaching Resource Program (TRP) have gained wide popularity among Foreign Language schools since its application. The main achievements of this platform system, reflected in the design of digital products, include resources construction, platform construction, development and learning, writing drills, grammar test, composition evaluation, writing research, comments and some other digital.

The main content of "TRP" system includes management system, teaching resources, learning platform, self testing tool and software platform. Firstly, server, the top management, achieves its service mainly through daily network management. Server manages "data" and "text". Secondly, the three basic functions of "the manager end" covers "online monitoring", "user management", "curriculum management"[2]. With this function, the instructors can freely manage each writing team and immediately upload those compositions and finish online marking. Finally, as it is shown in the picture, the terminal management of the students is mainly reflected in the management and use of the teaching resources, such as "The classic resource" and "my resources".

Besides, there are writing scoring software and writing reviews generation software. The main function of this writing multiple scoring software covers "initial score", "structure" score ", the theme score" and "comprehensive evaluation"[3]. Through resource, digital, information, system management, the "TRP" system realizes network teaching. In this training system, different users and different roles have different network management rights and permissions.

In a word, TRP system provides a lot of methods and a broad space for the innovative teaching writing and it is greatly advancing English reform.

\subsection{Cooperative Learning}

Based on the multimedia teaching mode, the teacher is just a guide, supervisor and an assistant. He or she will make full use of teaching resources management platform to give assignments and the students should complete brain storm questions in reading and discussion in the warm-up section.

For example, when the teacher is to explain the writing methods of meeting minutes, he or she can mail those texts of a meeting discussion about flexitime to those writing groups. Then each group role-play the meeting in the classroom for about twenty minutes and each group member write down individual summary of the opinions. After that, with the reference to the minutes format from the teacher, each group mail their word document of their meeting minutes to the teacher. Finally, teachers make comments about their jobs and give opinions about those grammar mistakes and register property. In this cooperative learning process, everyone can express their views fully and freely. The communication between the teacher and students is strengthened and group members' connection is also enhanced. The writers will become more and more confident, active and positive. At the same time, they will have a profound understanding of team spirit. 


\subsection{Writing Evaluation}

With the help of TRP system, through mailbox or teaching resources platform online discussion, the students can send the mail electronic version of class composition to the teachers to get the comments and evaluation, including grammar, content, structure, etc. after that, the instructor can send back the evaluated article to the students for peer evaluation. At the end of the writing course, the teacher can assign preview and review writing tasks of the next lesson. Based on CAI teaching pattern, the teacher will no longer be the center and he or she serves as a guide and counselor.

\section{SUMMARY}

Compared with the traditional English writing teaching, the writing course in network environment would be more objective and targeted. Teachers can not only carry out "one to one" counseling for students but also promote the communication among the writing groups. In the pre-writing section, the various reading materials can be fully shared and discussed which can improve the learning efficiency and help the students to find ways to solve difficult problems. With the help of various writing training methods, for the students, they can quickly form their individual writing and find the most suitable writing method. For the teachers, they can also expand their thinking because they not only can know the writing proficiency of English majors from the other universities but also can discuss the teaching methods with the English teachers over the world.

Above all, network teaching method combines the students' cognition and affection and provides opportunities for them to show their individual personalities and non- professional qualities, such as confidence, communication, cooperation, etc. It not only enhances their social awareness and confidence to succeed but also promotes different qualities of College students.

\section{REFERENCES}

[1] John H. \&Tim J. Computers in Language Learning. Collins ELT London and Glasgow.1984.

[2] Olsen, Solveig. (Ed.), (1985). Computer-aided instruction in the humanities. New York: MLA.

[3] M. Warschauer \& R. Kern (Eds).Network-Based Language Teaching: Concept and Practice. New York: Cambridge University Press.2000. 